\title{
A Single-Stage High Power Factor Power Supply for Providing an LED Street-Light Lamp Featuring Soft-Switching and Bluetooth Wireless Dimming Capability
}

\author{
Chun-An Cheng * ${ }^{\mathbb{C}}$, Hung-Liang Cheng $\left.\mathbb{(}\right)$, Chien-Hsuan Chang $\mathbb{(}$, En-Chih Chang, Wei-Shiang Hung, \\ Chin-Chih Lai and Long-Fu Lan
}

check for updates

Citation: Cheng, C.-A.; Cheng, H.-L.; Chang, C.-H.; Chang, E.-C.; Hung, W.-S.; Lai, C.-C.; Lan, L.-F. A SingleStage High Power Factor Power Supply for Providing an LED StreetLight Lamp Featuring Soft-Switching and Bluetooth Wireless Dimming Capability. Energies 2021, 14, 477 https://doi.org/10.3390/en14020477

Received: 7 December 2020

Accepted: 14 January 2021

Published: 18 January 2021

Publisher's Note: MDPI stays neutral with regard to jurisdictional claims in published maps and institutional affiliations.

Copyright: (c) 2021 by the authors. Licensee MDPI, Basel, Switzerland. This article is an open access article distributed under the terms and conditions of the Creative Commons Attribution (CC BY) license (https:/ / creativecommons.org/licenses/by/ $4.0 /)$.
Department of Electrical Engineering, I-Shou University, Kaohsiung City 84001, Taiwan; hlcheng@isu.edu.tw (H.-L.C.); chchang@isu.edu.tw (C.-H.C.); enchihchang@isu.edu.tw (E.-C.C.); isu10601014m@cloud.isu.edu.tw (W.-S.H.); isu10501001m@cloud.isu.edu.tw (C.-C.L.); isu10601018a@cloud.isu.edu.tw (L.-F.L.)

* Correspondence: cacheng@isu.edu.tw; Tel.: +886-7-657-7711 (ext. 6619)

\begin{abstract}
Light-emitting diode (LED) has the characteristics of environmental protection and energy saving, having become the lighting source of a new generation of street-light lamps. The traditional two-stage power supply for providing an LED street-light lamp is composed of an AC-DC converter with a power-factor-correction (PFC) function at the front stage and a DC-DC converter at the rear stage. The two-stage power supply for an LED street-light lamp has a large number of electronic components and costs, and the circuit efficiency is not high. Therefore, this paper presents a novel single-stage high power factor AC-DC power supply for providing an LED street-light lamp featuring soft-switching and Bluetooth wireless dimming capability through using smart tablets or smartphones to remote control the output power of the LED street-light lamp for achieving energysaving benefits. The proposed AC-DC LED power supply integrates an interleaved buck converter circuit with coupled inductors and a half-bridge LLC resonant converter circuit into a single-stage power conversion circuit. Moreover, the coupled inductor of the interleaved buck converter circuit is designed to operate in the discontinuous conduction mode, which can naturally achieve PFC. In addition, the two power switches in the novel LED power supply have zero-voltage switching (ZVS) characteristics, which can reduce the switching losses of the power switches. The two output diodes have the characteristics of zero-current switching (ZCS), which can reduce the conduction losses of the power diodes. This paper developed a single-stage prototype circuit for providing an 144 $\mathrm{W}$ (36 V/4 A)-rated LED street-light lamp. According to the experimental results of the prototype circuit with an AC input voltage of 110 volts, the presented single-stage LED power supply offers high power factor ( $\mathrm{PF}>0.99$ ), low input-current total harmonic distortion factor (THD $<3 \%$ ), and high efficiency (>89\%). In addition, this paper used the built-in Bluetooth wireless communication function of a smart tablet or smart phone to fulfill remote dimming control. By changing the duty ratio of the control signal, we could realize remote dimming control of $20 \%$ to $100 \%$ of the output LED street-light lamp power.
\end{abstract}

Keywords: Bluetooth; converter; light-emitting diode (LED); power factor correction (PFC); power supply; street-light; wireless dimming

\section{Introduction}

The street-light lamps widely installed on roads, streets, parks, squares, public places, and decorative outdoor lighting areas have the function of providing night lighting, being are usually lit at night or in the dark and extinguished in the early morning. The traditional street lighting source is a high-pressure mercury lamp featuring low installation cost. However, it has the disadvantages of poor luminous efficiency and high energy consumption, as well as the problems of mercury pollution and being difficult to start up in 
low-temperature circumstances. In recent years, high-pressure mercury lamps have been replaced by light-emitting diode (LED) street-lights with their attractive characteristics of environmental protection and energy-saving [1,2]. For instance, comparing an LED street-light lamp with a high-pressure mercury one under approximately the same output luminous flux, the LED version has a 50\% lower power consumption ( $120 \mathrm{~W}$ vs. $250 \mathrm{~W})$, a $50 \%$ higher lighting efficacy $(110 \mathrm{~lm} / \mathrm{W}$ vs. $52 \mathrm{~lm} / \mathrm{W})$, and a longer average lifetime $(50,000 \mathrm{~h}$ vs. $24,000 \mathrm{~h})[3,4]$. Generally, the power supply circuit of LED street-light lamps uses AC mains as the input power. The first stage is an AC-DC power converter with power factor correction (PFC) function and the second stage is a DC-DC power converter to provide the rated DC voltage and current required by the LED street-light lamp [5-8]. The traditional two-stage AC-DC high power factor power supply (HPFPS) for providing an LED street-light lamp includes an AC-DC boost converter as the first-stage circuit featuring PFC and a DC-DC half-bridge LLC resonant (HB-LLCR) converter as the second-stage circuit to supply the LED street-light lamp with rated power. Figure 1 shows the two-stage AC-DC power supply for providing an LED street-light lamp that consists of a boost converter with PFC and a HB-LLRC converter [8]. In their respective studies, [9-18] developed and implemented the integration of the first-stage AC-DC converter and the second-stage DC-DC converter into a single-stage LED power supply, which is characterized by improved circuit efficiency and reduction in the number of circuit components. An existing single-stage HPFPS for furnishing an LED street-light lamp merging with an interleaved boost converter and a HB-LLC converter was developed in [18], as depicted in Figure 2. The AC-DC power supplies as shown in Figures 1 and 2 for providing an LED street-light lamp are based on boost-type power conversion in the front-part circuit, and the voltage stresses of the DC-link capacitor and power switches are high.

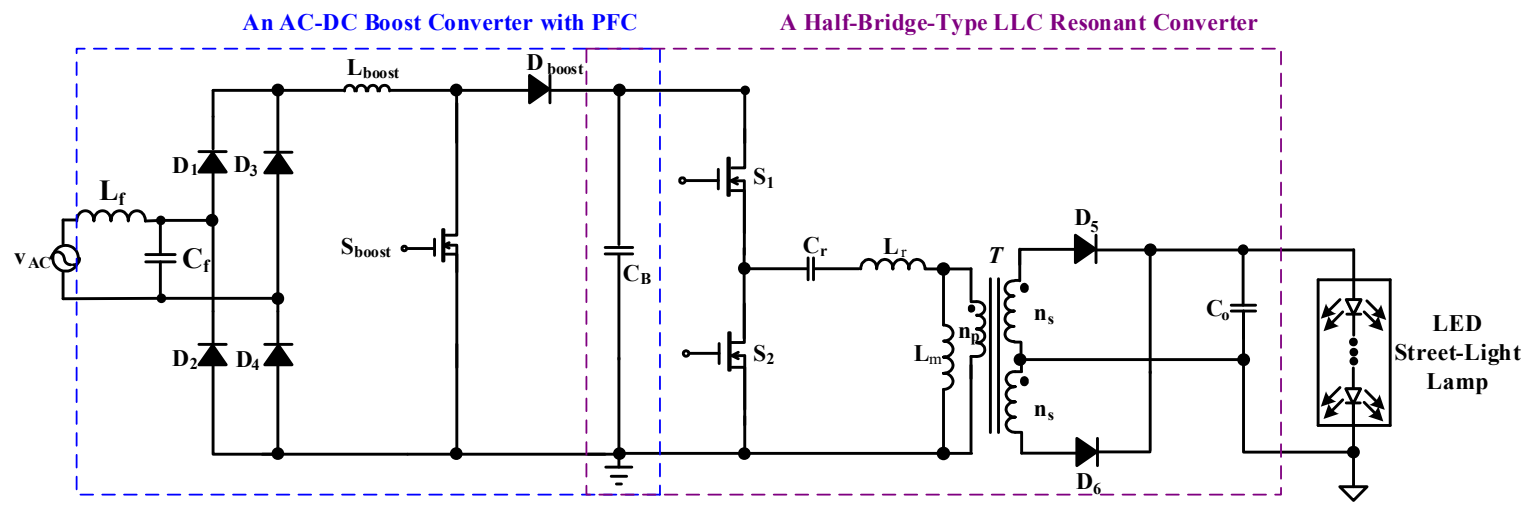

Figure 1. Traditional two-stage AC-DC power supply for providing a light-emitting diode (LED) street-light lamp [8].



Figure 2. An existing single-stage AC-DC power supply with power factor correction (PFC) for providing an LED street-light lamp [18]. 
In order to lower voltage stresses of the DC-link capacitor as well as the power switches, this paper presents a single-stage AC-DC HPFPS based on buck-type power conversion in the front-part circuit for providing an LED street-light lamp. In addition, the following will illustrate an energy-saving design example for outdoor lighting applications that can be applied to provide dimming control of the power supply for LED street-light lamps [19]. During the period from six to twelve o'clock in the evening, let the LED streetlight power supply produce $100 \%$ of the rated power to provide sufficient night lighting for the general public and passersby. After twelve o'clock in the morning, the output power of the LED street-light lamp can be reduced to $80 \%$ of the rated value. After two o'clock in the morning, the output power of the LED street-light lamp can be decreased to $60 \%$ of the rated value. After four o'clock in the morning, the demand for night lighting gradually decreases, and thus the output power of the LED street-light lamp can be reduced to $40 \%$ or $20 \%$ of the rated value. The power supply for the LED street-light lamp can be turned off during the period from six in the morning to six in the evening. The LED street-light power supply with dimming capability is suitable to adjust the output power in the above scheme in order to achieve the effect of energy saving and power saving [15,20,21]. Therefore, this paper developed a Bluetooth wireless dimming capability using a smart device (tablet or mobile phone) to carry out remote dimming control of the output power of the LED street-light lamp.

\section{Description and Circuit Analysis of the Proposed Single-Stage Power Supply for Providing an LED Street-Light Lamp}

This paper proposes a single-stage AC-DC HPFPS based on buck-type power conversion in the front-part circuit, as shown in Figure 3, for providing an LED street-light lamp; it integrates an AC-DC interleaved buck converter with PFC (including an inductor $\left(L_{f}\right)$, a capacitor $\left(C_{f}\right)$, a full-bridge rectifier $\left(D_{r 1}, D_{r 2}, D_{r 3}\right.$, and $\left.D_{r 4}\right)$, two coupled inductors $\left(L_{B 1}\right.$ and $L_{B 2} ; L_{B 3}$ and $\left.L_{B 4}\right)$, four diodes $\left(D_{B 1}, D_{B 2}, D_{B 3}\right.$, and $\left.D_{B 4}\right)$, two switches $\left(S_{1}\right.$ and $\left.S_{2}\right)$ as well as a DC-link capacitor $\left(C_{D C}\right)$, a DC-DC HB-LLCR converter (including switches $\left(S_{1}\right.$ and $S_{2}$ a), a DC-link capacitor $\left(C_{D C}\right)$, a resonant inductor $\left(L_{r}\right)$, a resonant capacitor $\left(C_{r}\right)$, a center-tapped transformer $(T)$ along with a magnetizing inductor $\left(L_{m}\right)$ and two output windings, two output diodes $\left(D_{1}\right.$ nd $\left.D_{2}\right)$, an output capacitor $\left(C_{o}\right)$, and the LED street-light lamp) into single-stage AC-DC power conversion circuit [22].

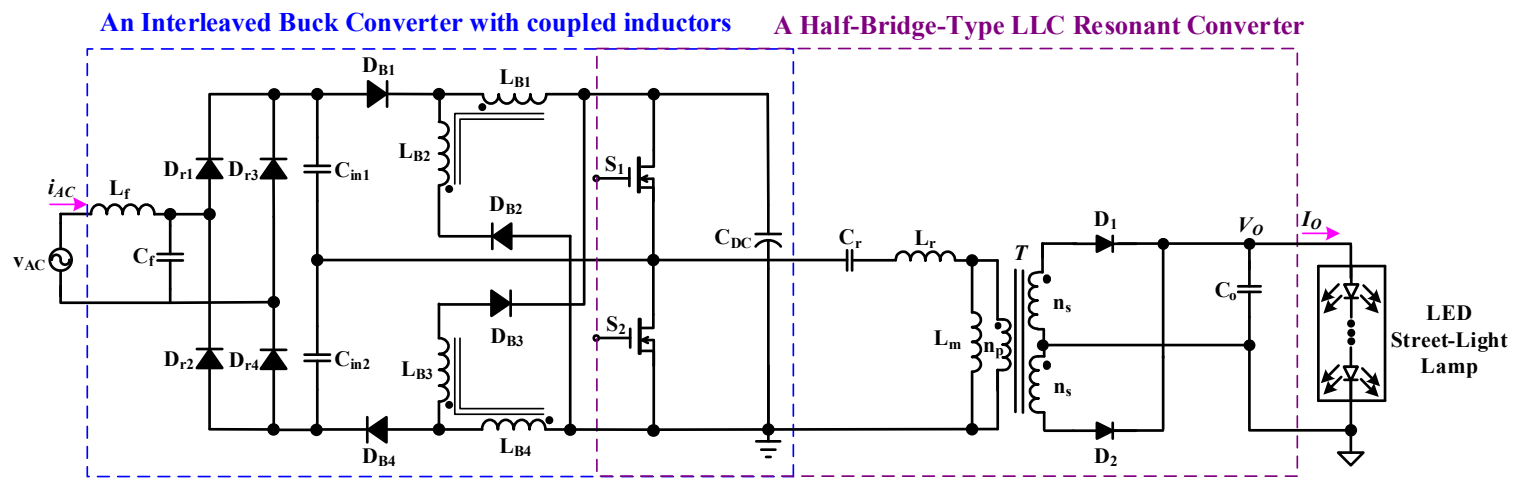

Figure 3. The proposed single-stage AC-DC power supply with PFC for providing an LED street-lighting lamp [22].

In order to facilitate the descriptions of the operation modes in the proposed LED power supply, we made the following assumptions during circuit analysis.

- The input AC mains voltage can be regarded as a fixed level in each high-frequency switching cycle, because its switching frequency is much greater than that one of the utility line.

- $\quad$ The rectified equivalent voltage sources $V_{R E C 1}$ and $V_{R E C 2}$ are respectively expressed as the voltage on capacitors $C_{i n 1}$ and $C_{i n 2}$ after the AC mains voltage is passed through the inductor $L_{f}$, the capacitor $C_{f}$, and the full-bridge rectifier. 
- The power switches $S_{1}$ and $S_{2}$ work complementarily, taking into account their essential diodes and parasitic capacitors.

- The forward-biased voltage drops and equivalent resistors of diodes $\left(D_{1}, D_{2}, D_{o 1}, D_{o 2}\right.$, $D_{03}$, and $D_{04}$ ) are ignored.

- The equivalent series resistors of all capacitors are neglected.

- $\quad$ Two coupled inductors $\left(L_{B 1}\right.$ and $L_{B 2} ; L_{B 3}$ and $\left.L_{B 4}\right)$ are arranged to work in discontinuous conduction mode (DCM).

Figure 4 displays the equivalent circuit diagram of the proposed single-stage AC-DC power supply for providing an LED street-light lamp.

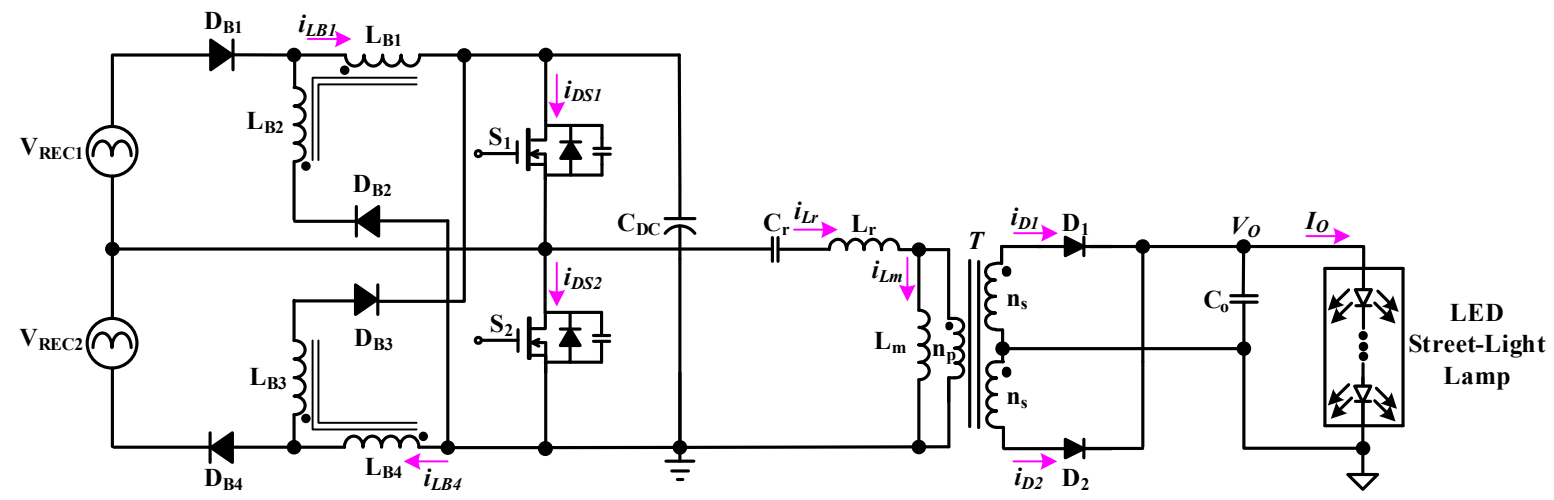

Figure 4. Equivalent circuit diagram of the proposed single-stage AC-DC power supply for providing an LED streetlight lamp.

The operational modes and theoretical waveforms of the presented LED power supply are shown in Figures 5 and 6, respectively, and the circuit analysis along with the operating of the LED power supply is described and discussed in detail below.

Mode 1 (the equivalent circuit as shown in Figure 5a): suppose that in the previous mode, the energy stored in the parasitic capacitor of the power switch $S_{1}$ is released, so that the switch voltage $v_{D S 1}$ drops to zero, causing the essential diode of the switch $S_{1}$ to be turned on at time $t_{0}$. The resonant inductor $L_{r}$ and the magnetizing inductor $L_{m}$ offer energy to the parasitic capacitor of the power switch $S_{2}$ and the DC-link capacitor $C_{D C}$ and the resonant capacitor $C_{r}$ by way of the essential diode of the switch $S_{1}$, and offer energy to the output capacitor $C_{o}$ and the LED street-light lamp via the transformer $T$ and the output diode $D_{1}$. Since the diode $D_{B 3}$ is forward-biased and turned on in the previous mode, the coupled inductors $L_{B 3}$ and $L_{B 4}$ offer energy to the DC-link capacitor $C_{D C}$ by means of the diode $D_{B 3}$. When the current $i_{L r}$ of the resonant inductor $L_{r}$ is decreased to zero, this mode finishes.

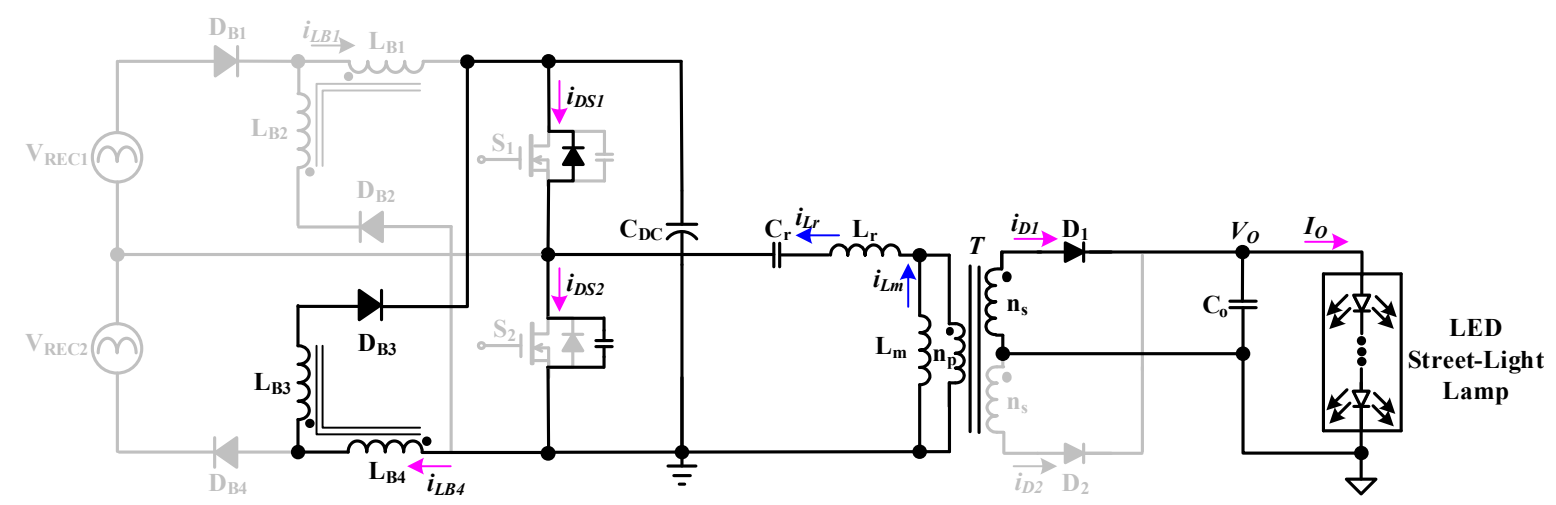

(a) Mode $1\left(t_{0} \leq t<t_{1}\right)$

Figure 5. Cont. 


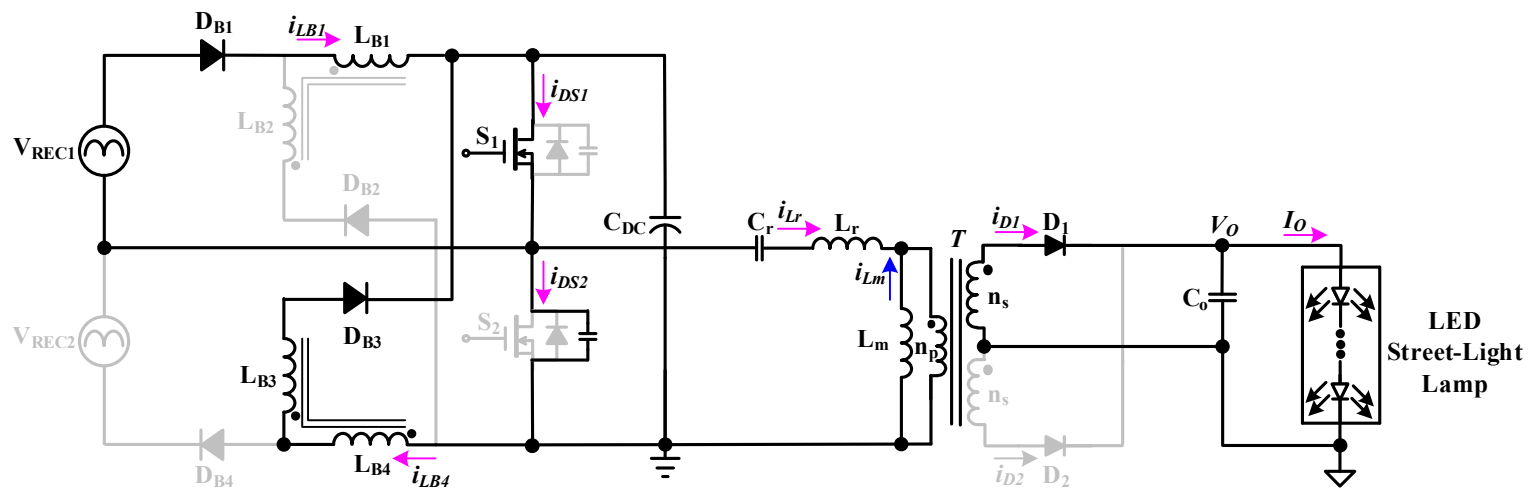

(b) Mode $2\left(t_{1} \leq t<t_{2}\right)$

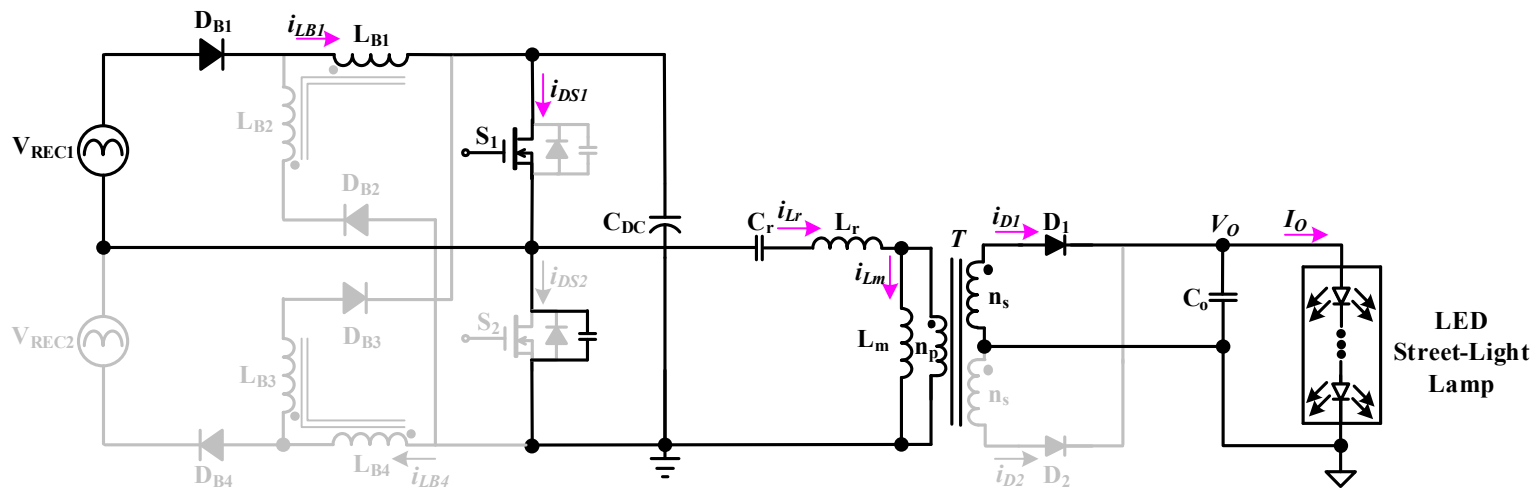

(c) Mode $3\left(t_{2} \leq t<t_{3}\right)$

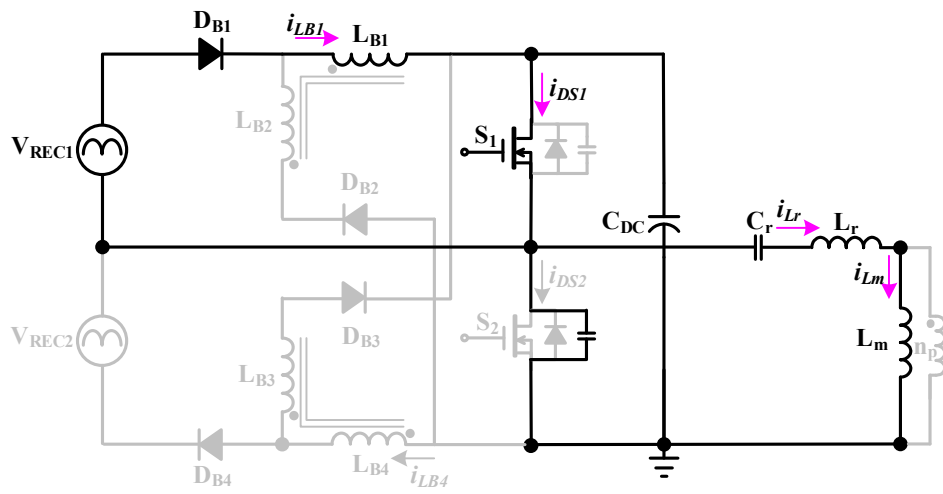

(d) Mode $4\left(t_{3} \leq t<t_{4}\right)$
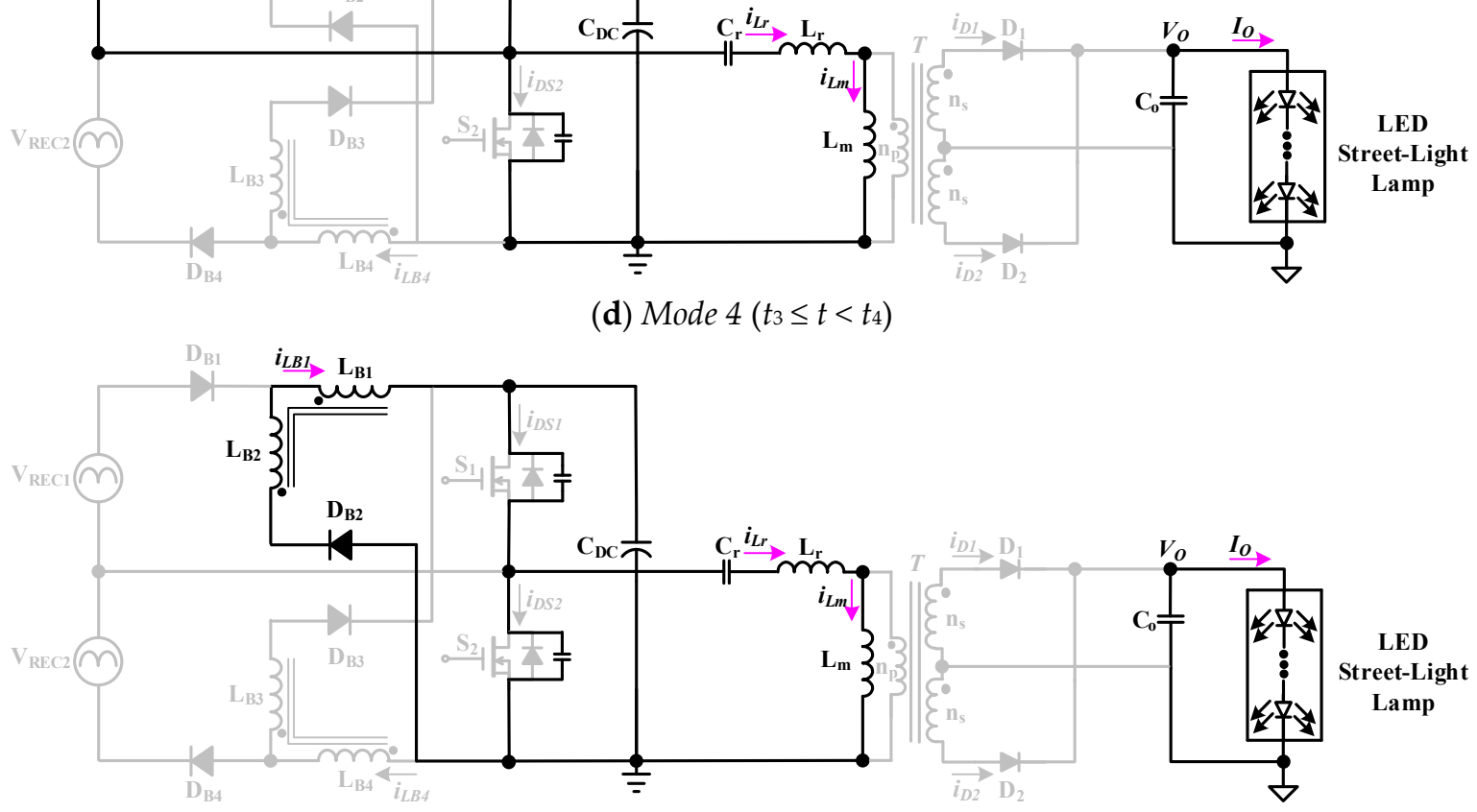

(e) Mode $5\left(t_{4} \leq t<t_{5}\right)$

Figure 5. Cont. 


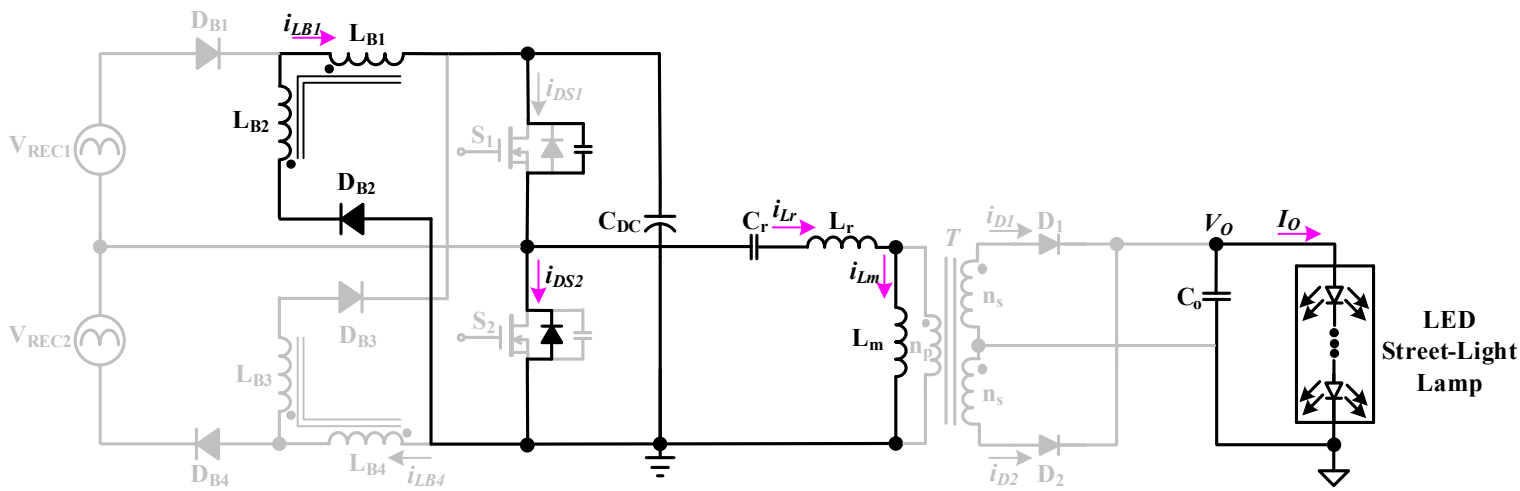

(f) Mode $6\left(t_{5} \leq t<t_{6}\right)$

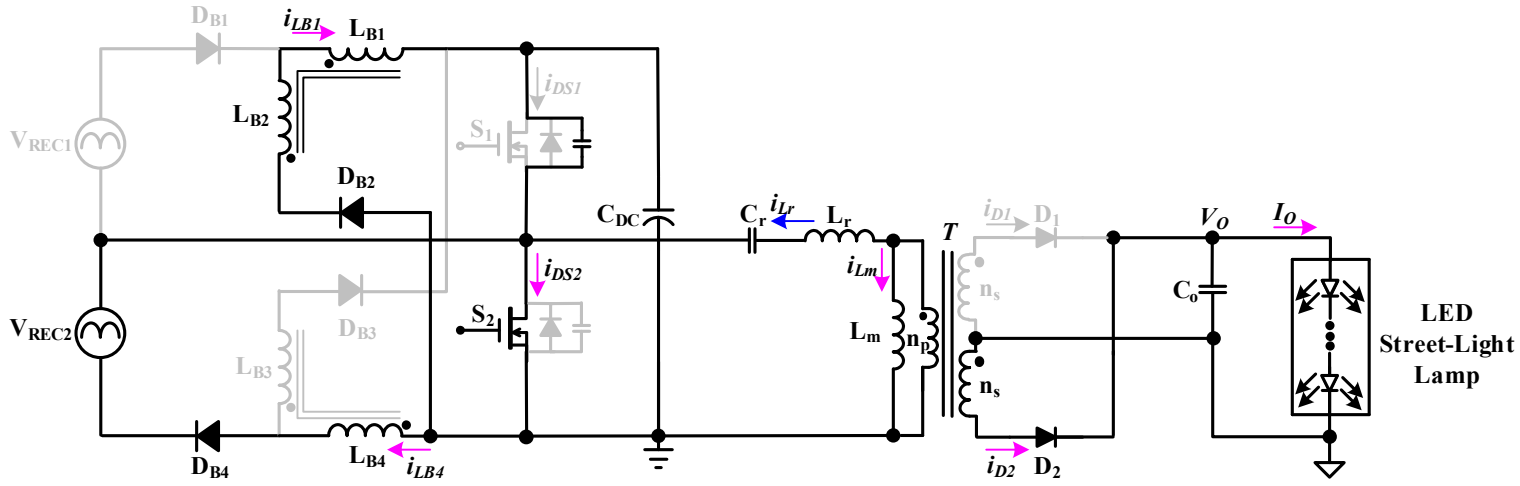

(g) Mode $7\left(t_{5} \leq t<t_{6}\right)$

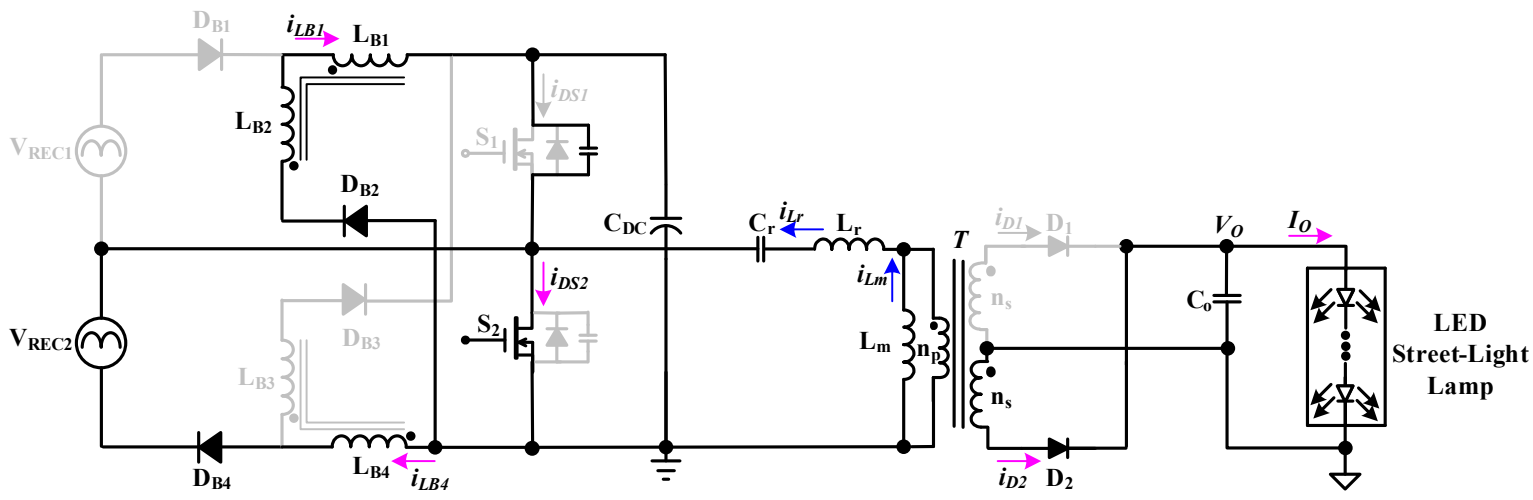

(h) Mode $8\left(t_{5} \leq t<t_{6}\right)$



(i) Mode $9\left(t_{5} \leq t<t_{6}\right)$

Figure 5. Cont. 




(j) Mode $10\left(t_{5} \leq t<t_{6}\right)$

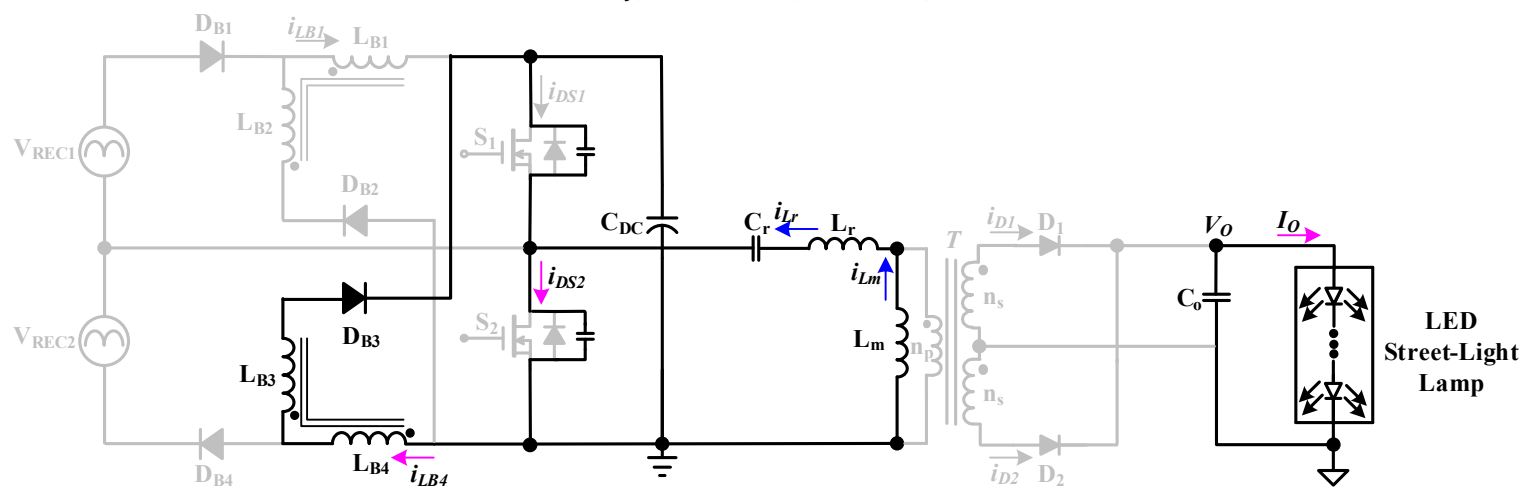

(k) Mode $11\left(t_{5} \leq t<t_{6}\right)$

Figure 5. Operation modes of the presented AC-DC power supply for providing an LED street-light lamp.

Mode 2 (the equivalent circuit as shown in Figure $5 b$ ): at time $t_{1}$, the power switch $S_{1}$ is driven and turned on, and has the characteristics of zero-voltage switching (ZVS). The rectified equivalent voltage source $V_{R E C 1}$ offers energy to the coupled inductor $L_{B 1}$ by way of the diode $D_{B 1}$ and the switch $S_{1}$, and the coupled inductor current $i_{L B 1}$ rises linearly. In addition, the diode $D_{B 2}$ is reversely biased and cannot be turned on. The DC-link capacitor $C_{D C}$, the resonant capacitor $C_{r}$, and the magnetizing inductor $L_{m}$ offer energy to the resonant inductor $L_{r}$ via the switch $S_{1}$, and offer energy to the output capacitor $C_{o}$ and the LED street-light lamp by means of the transformer $T$ and the output diode $D_{1}$. The DC-link capacitor $C_{D C}$ offers energy to the parasitic capacitor of the power switch $S_{2}$ by way of the switch $S_{1}$. The coupled inductors $L_{B 3}$ and $L_{B 4}$ continuously offer energy to the DC-link capacitor $C_{D C}$ by means of the diode $D_{B 3}$. When the coupled inductor current $i_{L B 4}$ drops to zero, this mode completes.

Mode 3 (the equivalent circuit as shown in Figure $5 c$ ): the rectified equivalent voltage source $V_{R E C 1}$ keeps on providing energy to the inductor $L_{B 1}$ by way of the diode $D_{B 1}$ and the switch $S_{1}$, and the inductor current $i_{L B 1}$ goes on increasing linearly. The DC-link capacitor $C_{D C}$ and the resonant capacitor $C_{r}$ continuously offer energy to the resonant inductor $L_{r}$ and the magnetizing inductor $L_{m}$ by means of the switch $S_{1}$, and supply energy to the output capacitor $C_{o}$ and the LED street-light lamp by way of the transformer $T$ and the output diode $D_{1}$. The DC-link capacitor $C_{D C}$ continuously offers energy to the parasitic capacitor of the power switch $S_{2}$ by means of the switch $S_{1}$. When the diode current $i_{D 1}$ drops to zero at time $t_{3}$, this mode ends.

Mode 4 (the equivalent circuit as shown in Figure $5 d$ ): the rectified equivalent voltage source $V_{R E C 1}$ holds on providing energy to the inductor $L_{B 1}$ by way of the diode $D_{B 1}$ and the switch $S_{1}$, and the inductor current $i_{L B 1}$ keeps on rising linearly. The DC-link capacitor $C_{D C}$ and the resonant capacitor $C_{r}$ continuously offer energy to the resonant inductor $L_{r}$ and the magnetizing inductor $L_{m}$ through the switch $S_{1}$. The DC-link capacitor $C_{D C}$ continuously supplies energy from the switch $S_{1}$ to the parasitic capacitor of the power 
switch $S_{2}$. The capacitor $C_{o}$ provides energy to the LED street-light lamp. When switch $S_{1}$ is turned off at time $t_{4}$, this mode completes.

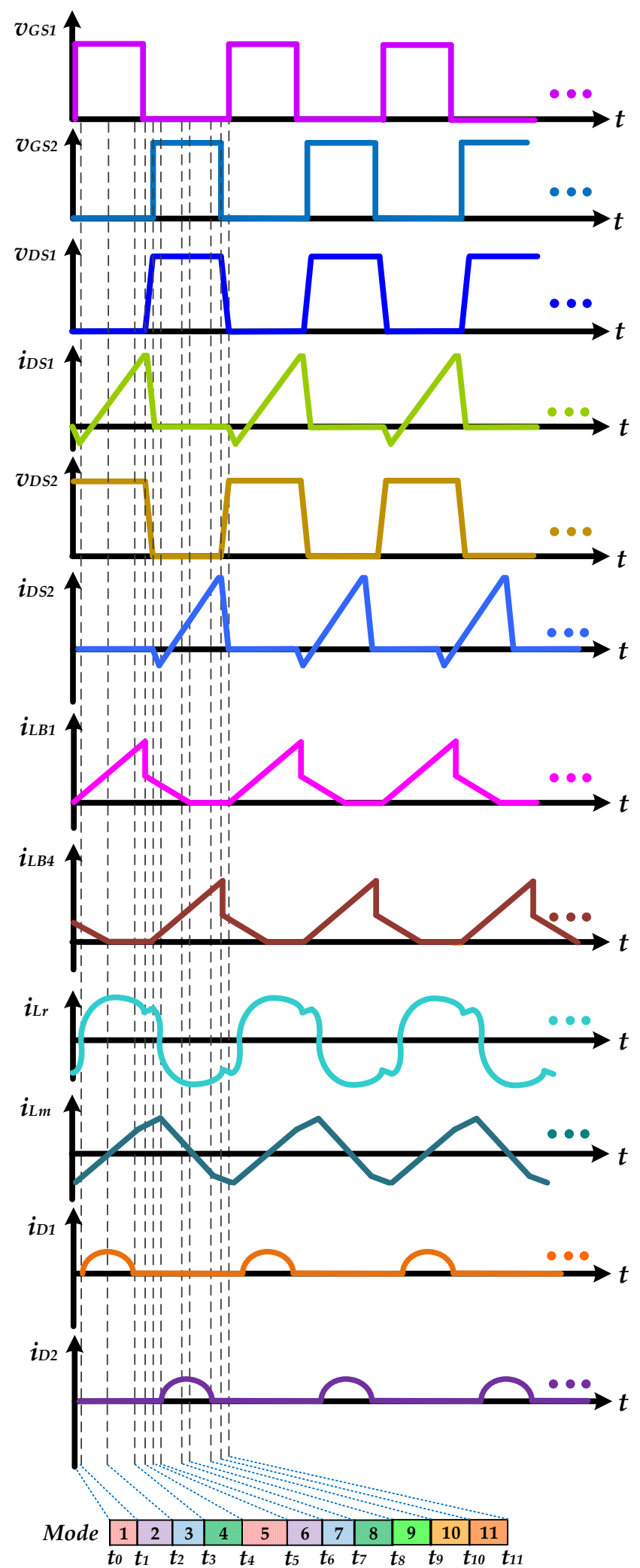

Figure 6. Theoretical waveforms of the presented AC-DC power supply for providing an LED street-light lamp. 
Mode 5 (the equivalent circuit as shown in Figure 5e): when the switch $S_{1}$ is turned off, the diode $D_{B 2}$ is turned on for being forward-biased, and the coupled inductors $L_{B 1}$ and $L_{B 2}$ offer energy to the DC-link capacitor $C_{D C}$ by way of the diode $D_{B 2}$, and the inductor current $i_{L B 1}$ decreases linearly. The DC-link capacitor $C_{D C}$ and the parasitic capacitor of the power switch $S_{2}$ offer energy to the parasitic capacitor of the power switch $S_{1}$, the resonant capacitor $C_{r}$, the resonant inductor $L_{r}$ and the magnetizing inductor $L_{m}$. The capacitor $C_{o}$ continuously supplies energy to the LED street-light lamp. When the switching voltage $v_{D S 2}$ drops to zero at time $t_{5}$, this mode completes.

Mode 6 (the equivalent circuit as shown in Figure 5f): since in the previous mode, the energy stored in the parasitic capacitor of the switch $S_{2}$ is released, the switch voltage $v_{D S 2}$ drops to zero, which causes the essential diode of the switch $S_{2}$ to conduct. The coupled inductors $L_{B 1}$ and $L_{B 2}$ go on offering energy to the DC-link capacitor $C_{D C}$ by way of the diode $D_{B 2}$, and the inductor current $i_{L B 1}$ keeps on showing a linear decrease. The DC-link capacitor $C_{D C}$, the resonant inductor $L_{r}$, and the magnetizing inductor $L_{m}$ continuously supply energy to the resonant capacitor $C_{r}$ and the parasitic capacitor of the power switch $S_{1}$ by means of the essential diode of the switch $S_{2}$, and the magnetizing inductor current $i_{L m}$ decreases linearly. The output capacitor $C_{o}$ holds on providing energy to the LED street-light lamp. When the switch $S_{2}$ is turned on, this mode ends.

Mode 7 (the equivalent circuit as shown in Figure $5 \mathrm{~g}$ ): the power switch $S_{2}$ is driven and turned on, and has the characteristics of ZVS. The rectified equivalent voltage source $V_{R E C 2}$ offers energy to the inductor $L_{B 4}$ by way of the diode $D_{B 4}$ and the switch $S_{2}$, and the inductor current $i_{L B 4}$ rises linearly. In addition, the diode $D_{B 3}$ is reversely biased and cannot be turned on. The coupled inductors $L_{B 1}$ and $L_{B 2}$ continuously provide energy to the DC-link capacitor $C_{D C}$ by means of the diode $D_{B 2}$, and the inductor current $i_{L B 1}$ goes on showing a linear decrease. The DC-link capacitor $C_{D C}$ offers energy to the parasitic capacitor of the switch $S_{1}$ by way of the power switch $S_{2}$. The resonant capacitor $C_{r}$ and the magnetizing inductor $L_{m}$ offer energy to the resonant inductor $L_{r}$, the output capacitor $C_{o}$, and the LED street-light lamp by means of the switch $S_{2}$, the transformer $T$, and the diode $D_{2}$, and the magnetizing inductor current $i_{L m}$ keeps on showing a linear decrease. When the magnetizing inductor current $i_{L m}$ reaches zero at time $t_{7}$, this mode ends.

Mode 8 (the equivalent circuit as shown in Figure 5h): the rectified equivalent voltage source $V_{R E C 2}$ keeps on offering energy to the inductor $L_{B 4}$ by way of the diode $D_{B 4}$ and the switch $S_{2}$, and the inductor current $i_{L B 4}$ keeps on rising linearly. The coupled inductors $L_{B 1}$ and $L_{B 2}$ go on providing energy to the DC-link capacitor $C_{D C}$ by way of the diode $D_{B 2}$, and the inductor current $i_{L B 1}$ goes on showing a linear decrease. The DC-link capacitor $C_{D C}$ continuously supplies energy to the parasitic capacitor of the switch $S_{1}$ by means of the power switch $S_{2}$. The resonant capacitor $C_{r}$ offers energy to the resonant inductor $L_{r}$, the magnetizing inductor $L_{m}$, the output capacitor $C_{0}$, and the LED street-light lamp by way of the switch $S_{2}$, the transformer $T$ and the diode $D_{2}$. When the coupled inductor current $i_{L B 1}$ drops to zero, this mode completes.

Mode 9 (the equivalent circuit as shown in Figure 5i): the rectified equivalent voltage source $V_{R E C 2}$ holds on providing energy to the inductor $L_{B 4}$ by way of the diode $D_{B 4}$ and the switch $S_{2}$, and the inductor current $i_{L B 4}$ keeps on rising linearly. The DC-link capacitor $C_{D C}$ continuously provides energy to the parasitic capacitor of the switch $S_{1}$ by means of the power switch $S_{2}$. The resonant capacitor $C_{r}$ continuously supplies energy to the resonant inductor $L_{r}$, magnetizing inductor $L_{m}$, output capacitor $C_{0}$, and the LED street-light lamp by way of the switch $S_{2}$, the transformer $T$, and the diode $D_{2}$. When the diode current $i_{D 2}$ drops to zero at time $t_{9}$, this mode completes.

Mode 10 (the equivalent circuit as shown in Figure 5j): the rectified equivalent voltage source $V_{R E C 2}$ continuously supplies energy to the inductor $L_{B 4}$ by means of the diode $D_{B 4}$ and the switch $S_{2}$, and the inductor current $i_{L B 4}$ continues to show a linear increase. The DC-link capacitor $C_{D C}$ continuously offers energy to the parasitic capacitor of the switch $S_{1}$ by way of the power switch $S_{2}$. The resonant capacitor $C_{r}$ continuously offers energy to the resonant inductor $L_{r}$ and the magnetizing inductor $L_{m}$ by means of the switch $S_{2}$. The 
output capacitor $C_{o}$ offers energy to the LED street-light lamp. When switch $S_{2}$ is turned off at time $t_{10}$, this mode completes.

Mode 11 (the equivalent circuit as shown in Figure 5k): when the switch $S_{2}$ is turned off, the diode $D_{B 3}$ is forwardly biased and turned on, and the coupled inductors $L_{B 3}$ and $L_{B 4}$ offer energy to the DC-link capacitor $C_{D C}$ by way of the diode $D_{B 3}$, and the inductor current $i_{L B 4}$ presents a linear decrease. The parasitic capacitor of the power switch $S_{1}$ and the resonant capacitor $C_{r}$ provide energy to the resonant inductor $L_{r}$, the magnetizing inductor $L_{m}$, and the DC-link capacitor $C_{D C}$. The output capacitor $C_{o}$ continues to provide energy to the LED street-light lamp. When the voltage $v_{D S 1}$ of the parasitic capacitor of the switch $S_{1}$ drops to zero at time $t_{11}$, this mode completes. After that, the circuit returns to operate Mode 1.

\section{Design Considerations in the Presented Single-Stage AC-DC Power Supply for Providing an LED Street-Light Lamp}

3.1. Design of the Coupled Inductors

The input utility-line voltage can be expressed by

$$
v_{A C}(t)=\sqrt{2} v_{A C-r m s} \sin \left(2 \pi f_{A C} t\right)
$$

where $v_{A C-r m s}$ and $f_{A C}$ are the root mean square (rms) value and the frequency of the input utility-line voltage, respectively. Figure 7 shows the theoretical waveforms of the coupled inductors' currents $i_{L B 1}$ and $i_{L B 4}$ along with the input utility-line current $i_{A C}$ at the positive half-cycle. The peak value of the coupled inductor current $i_{L B 1}$ is obtained as

$$
i_{L B 1-p k}(t)=\frac{\left|\sqrt{2} v_{A C-r m s} \sin \left(2 \pi f_{A C} t\right)\right|}{2 L_{B 1} f_{S}} d u t y
$$

where $f_{S}$ and duty are the switching frequency and the duty cycle of the gate-driving signals of two power switches, respectively. In each switching period, the input mains current $i_{A C}(t)$ is equal to two times average level of the coupled-inductor current $i_{L B 1-p k}(t)$, and can be represented by

$$
i_{A C}(t)=\frac{2}{T_{S}} \int_{0}^{T_{S}} i_{L B 1-p k}(t) d t=\frac{\sqrt{2} v_{A C-r m S} \sin \left(2 \pi f_{A C} t\right)}{L_{B 1} f_{S}} d u t y^{2}
$$



Figure 7. Theoretical waveforms of the coupled inductors currents $i_{L B 1}$ and $i_{L B 4}$ along with the input utility-line current $i_{A C}$ at the positive half-cycle. 
Combining (1) with (3), the average input power $P_{I N}$ is indicated by

$$
P_{I N}=\frac{1}{T_{S}} \int_{0}^{T_{S}} v_{A C}(t) \cdot i_{A C}(t) d t=\frac{v_{A C-r m s}{ }^{2}}{L_{B 1} f_{S}} d u t y^{2}
$$

The relationship between the rated-output LED power $P_{o}$ and the input power $P_{\text {in }}$ is given by

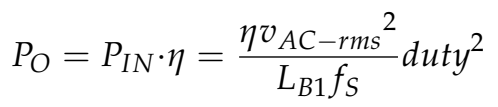

where $\eta$ is the estimated circuit efficiency of the LED power supply.

Rearranging (5), the mathematical expression for designing the coupled inductor $L_{B 1}$ is indicated by

$$
L_{B 1}=\frac{\eta v_{A C-r m s}^{2}}{P_{\text {lamp }} f_{S}} d u t y^{2}
$$

With a $\eta$ of 0.9 , a $v_{A C-r m s}$ of $110 \mathrm{~V}$, a $D$ of 0.5 , a $P_{o}$ of $144 \mathrm{~W}$, and a switching frequency $f_{S}$ of $100 \mathrm{kHz}$, the inductance of the coupled inductor $L_{B 1}$ is calculated as

$$
L_{B 1}=\frac{\eta v_{A C-r m s}{ }^{2}}{P_{\text {lamp }} f_{S}} d u t y^{2}=\frac{0.9 \cdot 110^{2}}{144 \cdot 100 k} 0.5^{2}=189.06 \mu \mathrm{H}
$$

In addition, in the prototype circuit, the coupled inductor $L_{B 1}$ is selected to be $180 \mu \mathrm{H}$, with the coupled inductors $L_{B 2}, L_{B 3}$, and $L_{B 4}$ having the same values as $L_{B 1}$.

\subsection{Design of the LLC Resonant Network}

According to the design equations of the LLC resonant network as shown in [23], the inductor $L_{r}$ can be expressed by

$$
L_{r}=\frac{Q_{r} R_{e q}}{2 \pi f_{r 1}}
$$

where $Q_{r}$ is the quality factor, $R_{e q}$ is represented as the equivalent output resistance referring to the primary side of the transformer $T$, and $f_{r 1}$ is the main resonant frequency of the LLC resonant network.

The magnetic inductor $L_{m}$ is given by

$$
L_{m}=A L_{r}
$$

where $A$ is the inductance ratio. The resonant capacitor $C_{r}$ is described as

$$
C_{r}=\frac{1}{\left(2 \pi f_{r 1}\right)^{2} L_{r}}
$$

With an $f_{r 1}$ of $100 \mathrm{kHz}$, an $R_{e q}$ of $182.4 \Omega$, an $A$ of 5 , and a $Q_{r}$ of 0.3 , the parameters of the LLC resonant network are respectively calculated as

$$
\begin{gathered}
L_{r}=\frac{Q_{r} R_{e q}}{2 \pi f_{r 1}}=\frac{0.3 \cdot 182.4}{2 \pi \cdot 100 k}=87.09 \mu \mathrm{H} \\
L_{m}=A L_{r}=5 \cdot 87.09 \mu=435.45 \mu \mathrm{H}
\end{gathered}
$$

and

$$
C_{r}=\frac{1}{\left(2 \pi f_{r 1}\right)^{2} L_{r}}=\frac{1}{(2 \pi \cdot 100 k)^{2} \cdot 87.09 \mu}=29.09 \mathrm{nF}
$$

In addition, the inductors $L_{r}$ and $L_{m}$, and capacitor $C_{r}$ are selected as $90 \mu \mathrm{H}, 450 \mu \mathrm{H}$, and $22 \mathrm{nF}$, respectively. 


\section{Experimental Results of the Prototype AC-DC Power Supply for Providing an LED Street-Light Lamp}

Table 1 shows the specifications of the experimental LED street-light lamp, with this paper completing the development of a single-stage prototype power supply for providing an $144 \mathrm{~W}$ (36 V/4 A)-rated LED street-light lamp suitable for an AC input utility-line voltage of $110 \mathrm{~V}$. Table 2 presents the utilized circuit components in the proposed singlestage AC-DC power supply for providing an LED street-light lamp.

Table 1. Specifications of the experimental LED street-light lamp.

\begin{tabular}{cc}
\hline Parameter & Value \\
\hline Input utility-line voltage $v_{A C}$ & $110 \mathrm{~V} \mathrm{(rms)}$ \\
Input utility-line frequency $f_{A C}$ & $60 \mathrm{~Hz}$ \\
Rated LED power & $144 \mathrm{~W}$ \\
Rated LED voltage & $36 \mathrm{~V}$ \\
Rated LED current & $4 \mathrm{~A}$ \\
\hline
\end{tabular}

Table 2. Circuit components utilized in the presented AC-DC power supply for supplying an LED street-light lamp.

\begin{tabular}{cc}
\hline Parameter & Value \\
\hline Capacitors $\left(C_{i n 1}, C_{i n 2}\right)$ & $330 \mathrm{nF}$ \\
Coupled inductors $\left(L_{B 1}\right.$ and $L_{B 2} ; L_{B 3}$ and $\left.L_{B 4}\right)$ & $179 \mu \mathrm{H}$ \\
Diodes $\left(D_{B 1}, D_{B 2}, D_{B 3}, D_{B 4}\right)$ & MUR460 \\
Power switches $\left(S_{1}, S_{2}\right)$ & STP20NM60 \\
DC-link capacitor $C_{D C}$ & $220 \mu \mathrm{F} / 450 \mathrm{~V}$ \\
Magnetizing inductor $L_{m}$ & $450 \mu \mathrm{H}$ \\
Resonant inductor $L_{r}$ & $90 \mu \mathrm{H}$ \\
Resonant capacitor $C_{r}$ & $22 \mathrm{nF}$ \\
Diodes $\left(D_{1}, D_{2}\right)$ & MBR30H100CT \\
Output capacitor $C_{o}$ & $2200 \mu \mathrm{F} / 63 \mathrm{~V}$ \\
\hline
\end{tabular}

Figure 8 demonstrates experimental waveforms of coupled inductor currents $i_{L B 1}$ and $i_{L B 4}$. Figure 9 presents the experimental waveforms of the power switch voltage $v_{D S 2}$ and the resonant inductor current $i_{L r}$. From the waveform, it is known that the voltage waveform leads the current waveform, and thus the resonant network has the characteristics of an inductive load. Figure 10 demonstrates the experimental waveforms of the power switch voltage $v_{D S 1}$ and current $i_{D S 1}$. It can be seen that ZVS was achieved on the power switch, which can reduce the switching losses of the power switch. Figure 11 presents the experimental waveforms of the power switch voltage $v_{D S 1}$ and the diode current $i_{D 1}$. The waveform diagram shows that the output diode had the characteristic of zero-current switching (ZCS), which can reduce the conduction loss of the power diode. Figure 12 presents the experimental waveform of the DC-link voltage $V_{D C}$, with the average level of the DC-link voltage being $228.7 \mathrm{~V}$. Figure 13 demonstrates the experimental waveforms of the output voltage $V_{O}$ and the output current $I_{O}$. The average levels of the output voltage and current were approximately $36 \mathrm{~V}$ and $4 \mathrm{~A}$, respectively.

Figure 14 shows the experimental waveforms of the input AC mains voltage $v_{A C}$ and current $i_{A C}$. It can be seen from the figure that the input $A C$ mains current followed the input $\mathrm{AC}$ mains voltage and that the phases of the two waveforms were the same, which resulted in a high power factor. Figure 15 demonstrates the comparisons between the measured harmonics of each order of the input AC mains current and the IEC 61000-3-2 Class C standard values through using a power analyzer (Tektronix PA 4000) at an AC input voltage of $110 \mathrm{~V}$. It can be seen from the figure that the measured harmonics of each order of the input $\mathrm{AC}$ mains current met the requirements of the specification. The measured power factor and total harmonic distortion factor of the input AC utility-line 
current were 0.9992 and $2.2954 \%$, respectively. In addition, the measured efficiency of the prototype LED power supply circuit was $89.53 \%$.

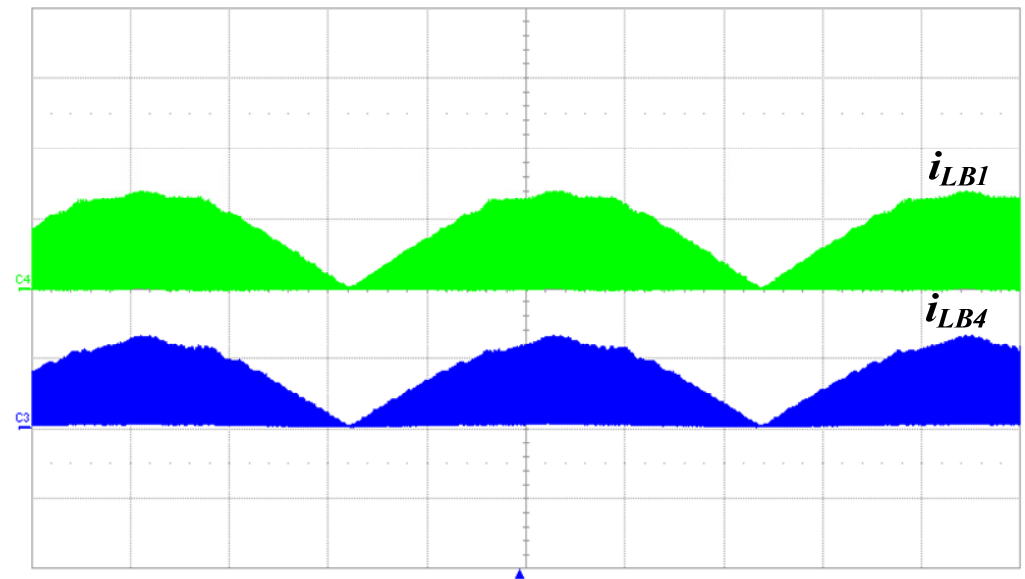

Figure 8. Experimental waveforms of the coupled-inductor currents $i_{L B 1}(5 \mathrm{~A} / \mathrm{div})$ and $i_{L B 4}(5 \mathrm{~A} / \mathrm{div})$; time scale: $2 \mathrm{~ms} /$ div.

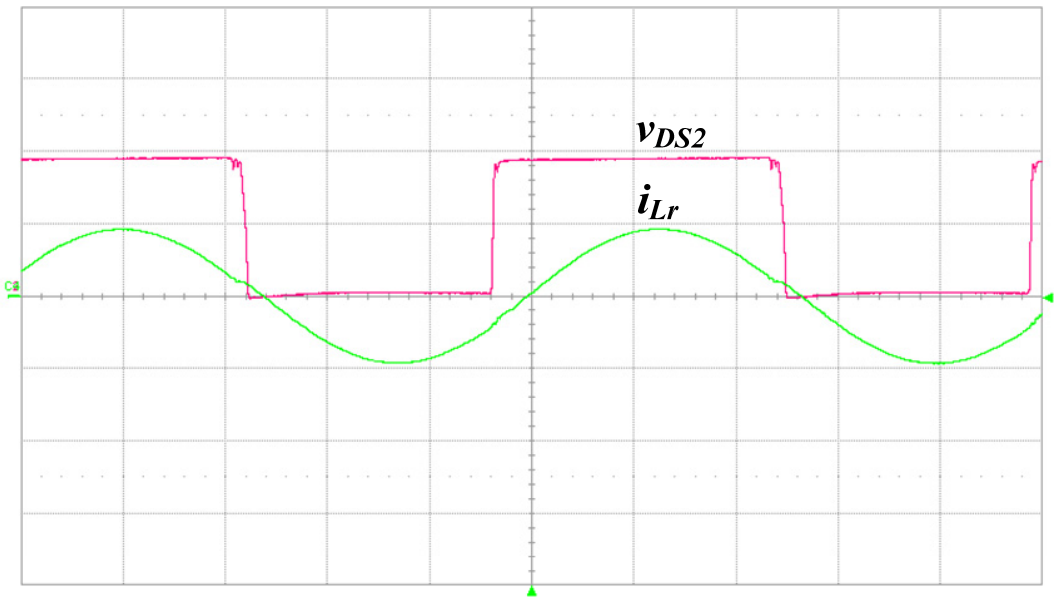

Figure 9. Experimental waveforms of the switch voltage $v_{D S 2}(100 \mathrm{~V} / \mathrm{div})$ and the resonant inductor current $i_{L r}(2 \mathrm{~A} / \mathrm{div})$; time scale: $2 \mu \mathrm{s} /$ div.

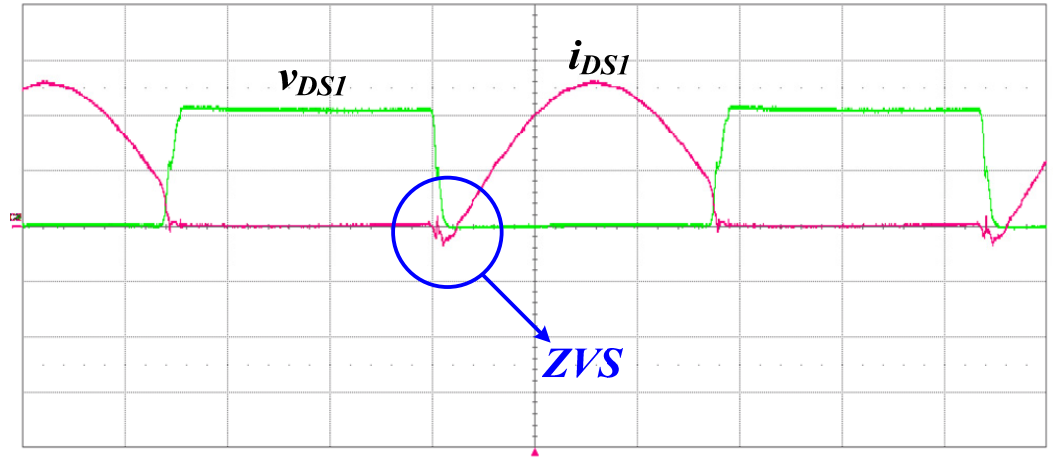

Figure 10. Experimental waveforms of the switch voltage $v_{D S 1}(100 \mathrm{~V} /$ div $)$ and the switch current $i_{D S 1}(1 \mathrm{~A} /$ div); time scale: $2 \mu \mathrm{s} /$ div. 


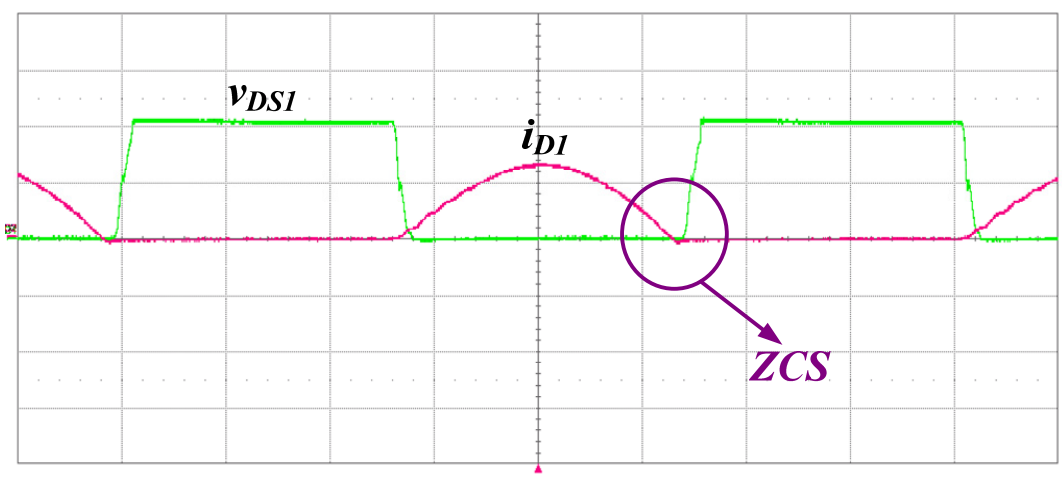

Figure 11. Experimental waveforms of the switch voltage $v_{D S 1}(100 \mathrm{~V} / \mathrm{div})$ and the output diode current $i_{D 1}(5 \mathrm{~A} / \mathrm{div})$; time scale: $2 \mu \mathrm{s} / \mathrm{div}$.

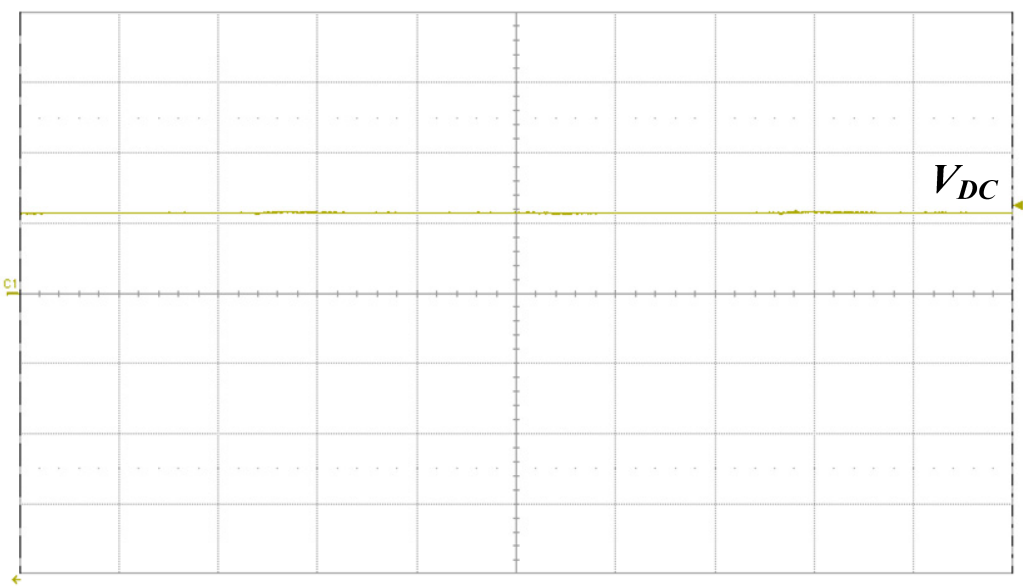

Figure 12. Experimental waveform of the DC-link voltage $V_{D C}(200 \mathrm{~V} / \mathrm{div})$; time scale: $2 \mu \mathrm{s} /$ div.

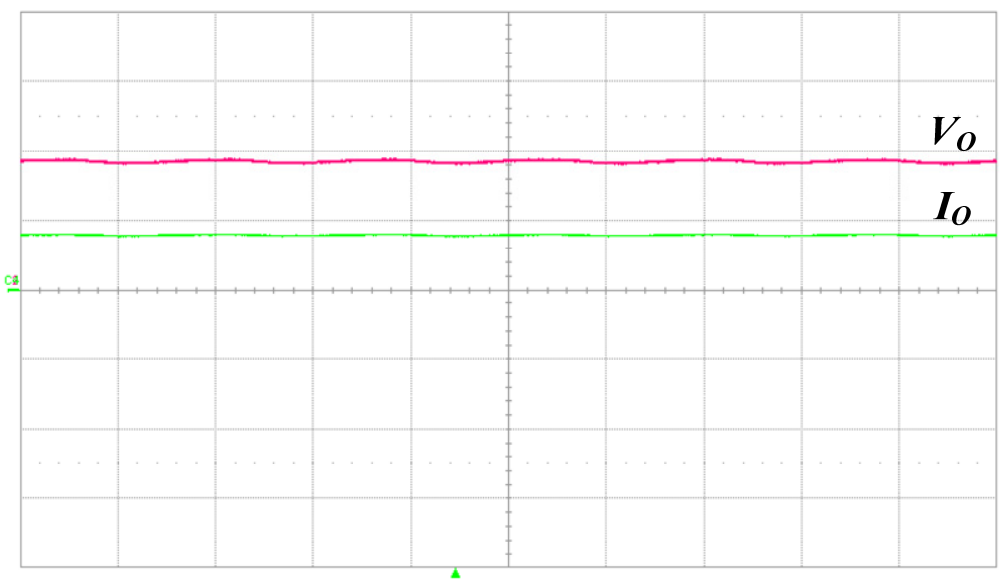

Figure 13. Experimental waveforms of the output LED voltage $V_{O}(20 \mathrm{~V} /$ div $)$ and the output LED current $I_{O}(5 \mathrm{~A} / \mathrm{div})$; time scale: $5 \mathrm{~ms} / \mathrm{div}$.

Table 3 shows the experimental results of the output LED voltage and output LED current ripples for the presented LED power supply at an input AC mains voltage of $110 \mathrm{~V}$. It is observed that the experimental voltage and current ripple factors were less than $4 \%$ and $2 \%$, respectively. Figure 16 is a photo of the proposed single-stage prototype power supply circuit that lights up the LED street-light lamp provided with an AC power source. Furthermore, Table 4 shows comparisons between the existing single-stage AC-DC LED power supply in reference [18] and the proposed one. It can be seen that the presented 
power supply possessed lower input AC mains current total harmonic distortion (THD) and better circuit efficiency in comparison to reference [18].

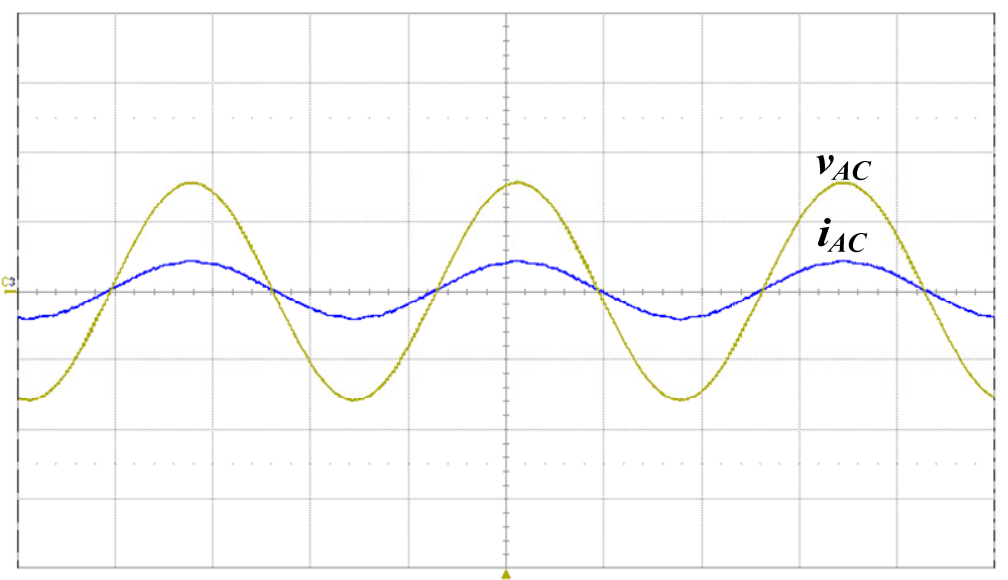

Figure 14. Experimental waveforms of the input AC mains voltage $v_{A C}(100 \mathrm{~V} / \mathrm{div})$ and the AC mains current $i_{A C}(5 \mathrm{~A} /$ div); time scale: $5 \mathrm{~ms} /$ div.



Figure 15. Measured harmonics of each order of the input AC mains current compared with the IEC 61000-3-2 Class C standard values.

Table 3. Experimental results of the output LED voltage and output LED current ripples of the presented AC-DC LED power supply at an input AC mains voltage of $110 \mathrm{~V}$.

\begin{tabular}{cc}
\hline Parameter & Value \\
\hline Average level of output LED voltage & $36.03 \mathrm{~V}$ \\
Peak-to-peak level of output LED voltage & $1.3 \mathrm{~V}$ \\
Voltage ripple factor & $3.61 \%$ \\
Average level of output LED current & $3.938 \mathrm{~A}$ \\
Peak-to-peak level of output LED current & $67 \mathrm{~mA}$ \\
Current ripple factor & $1.7 \%$ \\
\hline
\end{tabular}




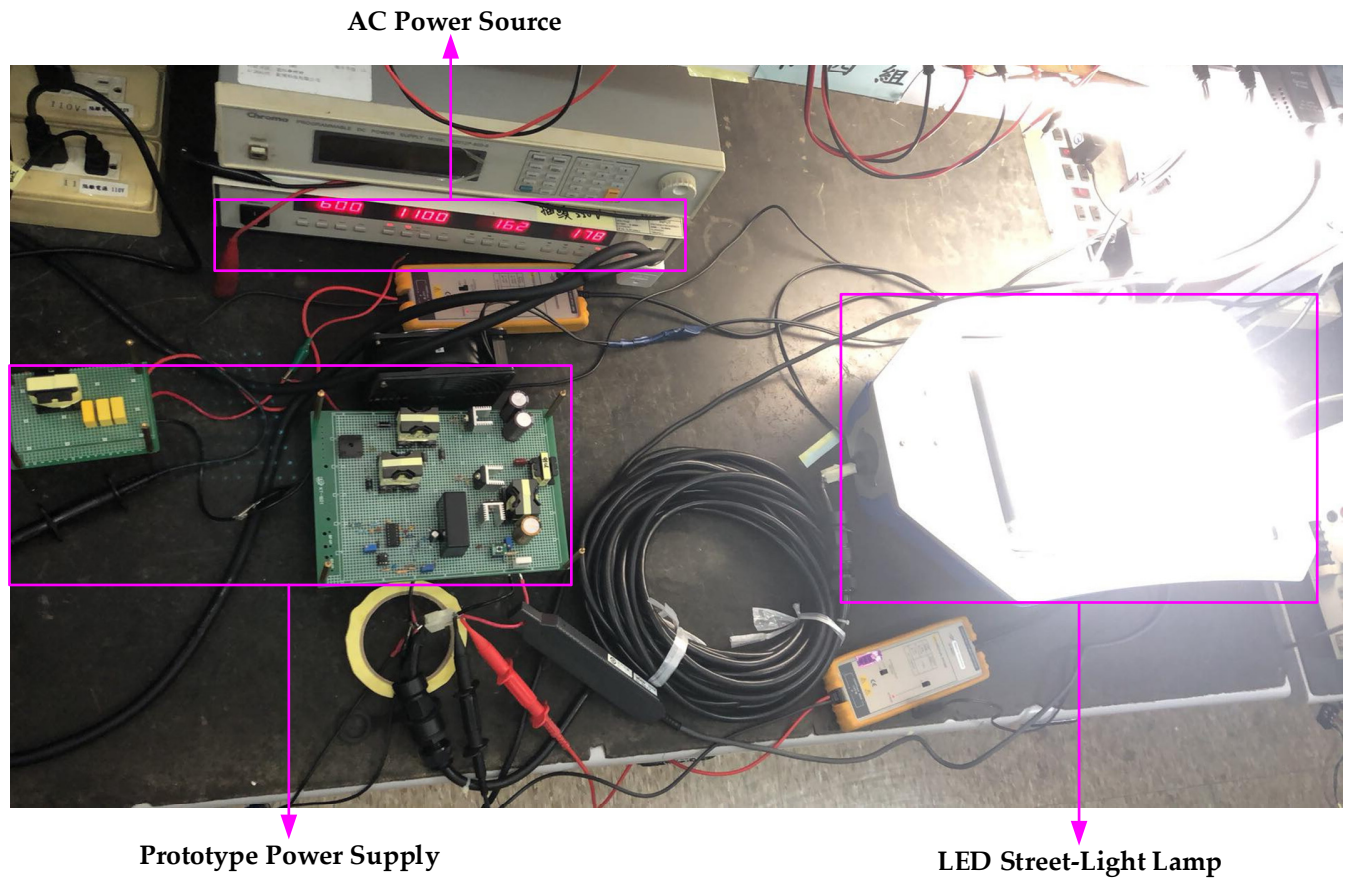

Figure 16. An overhead photograph of the proposed AC-DC power supply providing the LED street-light lamp with an input AC mains voltage of $110 \mathrm{~V}$.

Table 4. Comparisons between the existing single-stage AC-DC LED power supply in [18] and the presented version in this paper.

\begin{tabular}{ccc}
\hline Item & $\begin{array}{c}\text { Existing AC-DC LED Power Supply in } \\
\text { Reference [18] }\end{array}$ & $\begin{array}{c}\text { Presented } \\
\text { AC-DC LED Power Supply }\end{array}$ \\
\hline Circuit topology & Integration of interleaved boost converter and & $\begin{array}{c}\text { Integration of interleaved buck converter with } \\
\text { coupled-inductors and HB-LLCR converter }\end{array}$ \\
Number of required power switches & HB-LLCR converter & 2 \\
Number of required diodes & 2 & 10 \\
Number of required capacitors & 8 & 6 \\
Number of required magnetic components & 6 & 5 \\
Input utility-line voltage & 5 & $110 \mathrm{~V}$ \\
Output power & $110 \mathrm{~V}$ & $144 \mathrm{~W}(36 \mathrm{~V} / 4 \mathrm{~A})$ \\
Measured power factor & $>0.99$ & $>0.99$ \\
Measured current THD & $<10 \%$ & $>3 \%$ \\
Measured circuit efficiency & $>88 \%$ & $>89.5 \%$ \\
\hline
\end{tabular}

\section{Bluetooth Wireless Dimming Tests of the Prototype AC-DC Power Supply for Providing an LED Street-Light Lamp}

Figure 17 shows the architecture diagram of the proposed AC-DC power supply, which uses Bluetooth wireless communication technology to achieve the function of remote digital dimming control of the LED street-light lamp. In the wireless dimming control scheme of the LED street-light power supply circuit, the dimming control command sent by the administrator through the smart device (for example a smart tablet, a smart pad, or a smartphone) is sent to the microcontroller (Arduino NANO) via the Bluetooth wireless communication using a Bluetooth communication module (the model name is HC-05). Then, the dimming control signal from the microcontroller is sent to the power switch $S_{\text {dim }}$, which is connected in series with the LED street-light lamp and that is responsible for dimming control. By changing the duty ratio of the digital dimming control signal (from $100 \%$ to $20 \%$ ) fed into the power switch $S_{d i m}$, we can achieve the process of dimming and controlling the LED street-light lamp at $100 \%$ to $20 \%$ of the rated output power using Bluetooth wireless communication. 


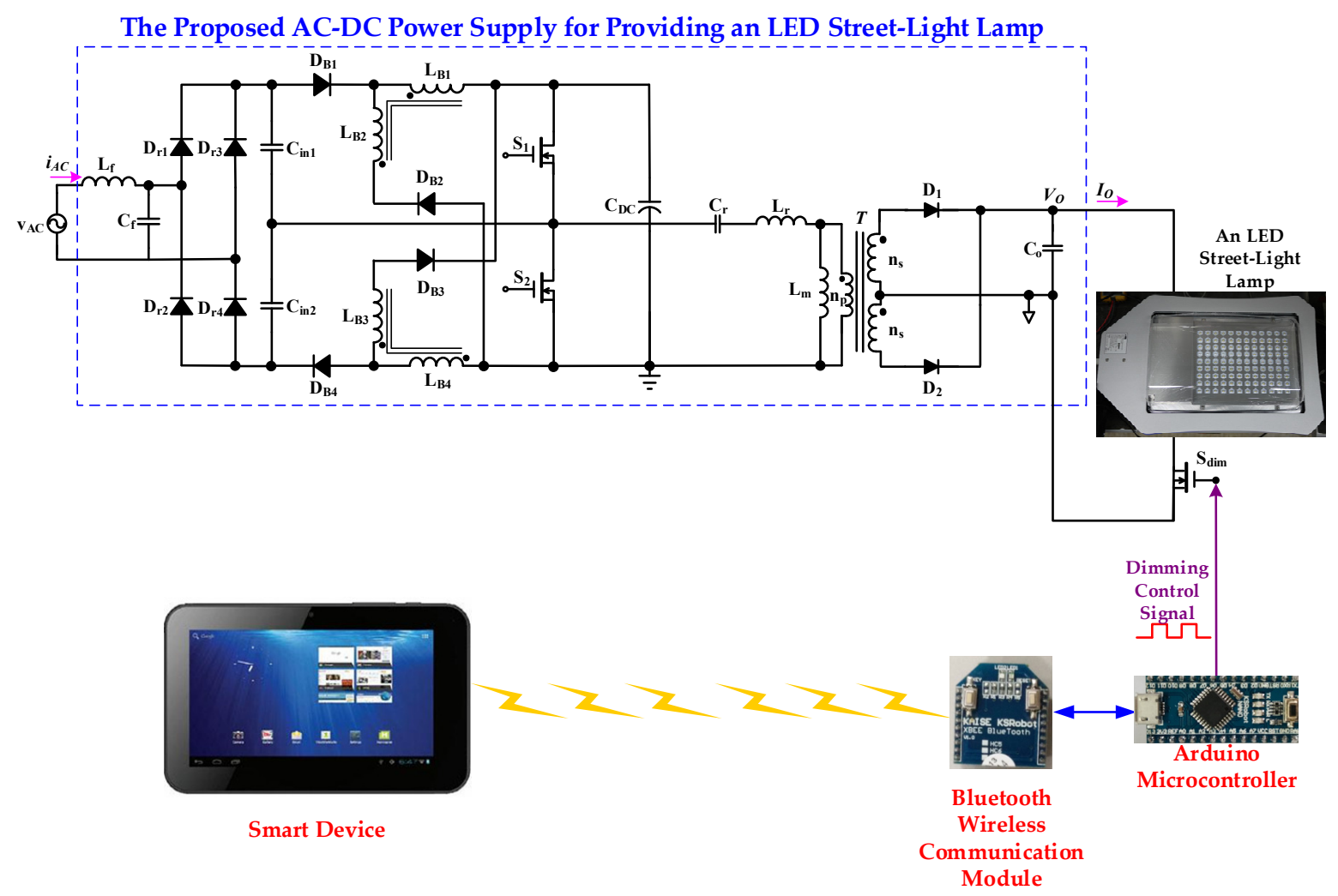

Figure 17. The architecture diagram of the proposed AC-DC power supply for providing an LED street-light lamp with Bluetooth wireless dimming capability.

Table 5 demonstrates the measured output current $I_{O}$ of the LED street-light lamp when the duty ratio of the dimming control signal ranged from $20 \%$ to $100 \%$. The measured output LED street-light lamp currents were $0.591 \mathrm{~A}, 1.063 \mathrm{~A}, 1.378 \mathrm{~A}, 1.811 \mathrm{~A}, 2.127 \mathrm{~A}$, $2.914 \mathrm{~A}, 3.347 \mathrm{~A}, 3.702 \mathrm{~A}$ and $3.938 \mathrm{~A}$ when the duty ratio of the dimming control signal was at $20 \%, 30 \%, 40 \%, 50 \%, 60 \%, 70 \%, 80 \%, 90 \%$, and $100 \%$, respectively. Moreover, the normalized value of the output LED street-light lamp current, $I_{O \text {, normalized }}$, is defined as the measured LED current divided by the rated one during the dimming process. By utilizing the measured data as shown in Table 5, the graph in Figure 18 shows the relationship between the duty ratio of the dimming control signal and the normalized output LED current $I_{O}$, normalized. Additionally, the minimum value of the normalized output LED current was 0.1471 , while the duty ratio of the dimming control signal was $20 \%$.

Table 5. The measured output LED current at different duty ratios of the dimming control signal during the Bluetooth wireless dimming process.

\begin{tabular}{cc}
\hline Duty Ratio of the Dimming Control Signal & Measured Output LED Current $\boldsymbol{I}_{\boldsymbol{O}}$ \\
\hline $20 \%$ & $0.591 \mathrm{~A}$ \\
$30 \%$ & $1.063 \mathrm{~A}$ \\
$40 \%$ & $1.378 \mathrm{~A}$ \\
$50 \%$ & $1.811 \mathrm{~A}$ \\
$60 \%$ & $2.127 \mathrm{~A}$ \\
$70 \%$ & $2.914 \mathrm{~A}$ \\
$80 \%$ & $3.347 \mathrm{~A}$ \\
$90 \%$ & $3.702 \mathrm{~A}$ \\
$100 \%$ & $3.938 \mathrm{~A}$ \\
\hline
\end{tabular}






Figure 18. The relationship between the duty ratio of dimming control signal and the normalized output LED current $I_{O, \text { normalized }}$.

\section{Conclusions}

Compared with high-pressure mercury lamps, LEDs have the advantages of long service life, high lighting efficiency, and low power consumption, having become a new generation of street light sources. This paper proposed and analyzed a single-stage AC-DC power supply, combining an interleaved buck converter with coupled inductors and an HBLLCR converter for providing an LED street-light lamp with features of high power factor and soft-switching. A prototype power supply for providing a $144 \mathrm{~W}$-rated LED streetlight lamp was successfully implemented and tested. In addition, this paper developed Bluetooth dimming applications for smart tablets or smart phones, having the function of remote wireless dimming to control the output power of the LED street-light lamp, achieving energy-saving benefits. Satisfactory experimental results acquired from the prototype LED power supply demonstrated that a high power-factor $(>0.99)$, a low utilityline current THD $(<3 \%)$, a high circuit efficiency $(>89 \%)$, ZVS on power switches, ZCS on power diodes, and Bluetooth wireless dimming control at $20-100 \%$ of rated output power.

Author Contributions: C.-A.C. and H.-L.C. conceived and invented the LED power supply circuit. C.-H.C. and E.-C.C. carried out the circuit simulations and designed the circuit parameters. W.-S.H. implemented the prototype LED power supply and measured experimental results. C.-C.L. and L.-F.L. accomplished Bluetooth wireless dimming tests of the LED power supply. C.-A.C. prepared and submitted the manuscript. All authors have read and agreed to the published version of the manuscript.

Funding: This research received no external funding.

Acknowledgments: The authors would like to express their appreciation for grant support from the Ministry of Science and Technology (MOST) of Taiwan under its grant with reference numbers MOST 107-2221-E-214-009, MOST 109-2221-E-214-011, and MOST 109-3116-F-006-020-CC1.

Conflicts of Interest: The authors declare no conflict of interest. 


\section{References}

1. Brañas, C.; Azcondo, F.; Alonso, J.M. Solid-state lighting: A system review. IEEE Ind. Electron. Mag. 2013, 7, 6-14. [CrossRef]

2. Almeida, P.S.; Camponogara, D.; Costa, M.A.D.; Braga, H.A.C.; Alonso, J.M. Matching LED and driver life spans: A review of different techniques. IEEE Ind. Electron. Mag. 2015, 9, 36-47. [CrossRef]

3. Specifications of OSRAM HQL 250W E40. Available online: https://www.any-lamp.com/osram-hql-250w-e40 (accessed on 30 December 2020).

4. Datasheet of LEDENVO ${ }^{\mathrm{TM}}$ LED Street Light. OSRAM. 2016. Available online: http://ls.osram.com.cn/pdf/EN_LEDENVO_ Street_Light_Datasheet_v1p2_20160926.pdf (accessed on 30 December 2020).

5. Wang, Y.; Guan, Y.; Xu, D.; Wang, W. A CLCL resonant DC/DC converter for two-stage LED driver system. IEEE Trans. Ind. Electron. 2016, 63, 2883-2891. [CrossRef]

6. Arias, M.; Lamar, D.G.; Linera, F.F.; Balocco, D.; Diallo, A.A.; Sebastian, J. Design of a soft-switching asymmetrical half-bridge converter as second stage of an LED driver for street lighting application. IEEE Trans. Power Electron. 2012, 27, $1608-1621$. [CrossRef]

7. Wang, Y.; Guan, Y.; Liang, X.; Wang, W.; Xu, D. Two-stage LED street lighting system based on a novel single-stage AC/DC converter. IET Power Electron. 2014, 7, 1374-1383. [CrossRef]

8. Naraharisetti, K.; Green, P.B. Design of 200 W Boost PFC Plus HB LLC Resonant Converter with IR1155, IRS27952 and IR11688. Application Note, Infineon. Available online: http:/ / www.infineon.com (accessed on 30 December 2020).

9. Camponogara, D.; Ferreira, G.F.; Campos, A.; Dalla Costa, M.A.; Garcia, J. Offline LED driver for street lighting with an optimized cascade structure. IEEE Trans. Ind. Appl. 2013, 49, 2437-2443. [CrossRef]

10. Arias, M.; Lamar, D.G.; Sebastian, J.; Balocco, D.; Diallo, A. High-efficiency LED driver without electrolytic capacitor for street lighting. IEEE Trans. Ind. Appl. 2013, 49, 127-137. [CrossRef]

11. Cheng, C.A.; Cheng, H.L.; Chung, T.Y. A novel single-stage high-power-factor LED street-lighting driver with coupled inductors. IEEE Trans. Ind. Appl. 2014, 50, 3037-3045. [CrossRef]

12. Cheng, H.L.; Lin, C.W. Design and implementation of a high power-factor LED driver with zero-voltage switching-on characteristics. IEEE Trans. Power Electron. 2014, 29, 4949-4958. [CrossRef]

13. Cheng, C.A.; Chang, C.H.; Chung, T.Y.; Yang, F.L. Design and implementation of a single-stage driver for supplying an LED street-lighting module with power factor corrections. IEEE Trans. Power Electron. 2015, 30, 956-966. [CrossRef]

14. Wang, Y.; Guan, Y.; Ren, K.; Wang, W.; Xu, D. A single-stage LED driver based on DCM boost circuit and LLC converter for street lighting system. IEEE Trans. Ind. Electron. 2015, 62, 5446-5457. [CrossRef]

15. Cheng, C.A.; Chung, T.Y. A single-stage LED streetlight driver with PFC and digital-PWM-dimming capability. Int. J. Circuit Theory Appl. 2016, 44, 1942-1958. [CrossRef]

16. Luo, Q.; Huang, J.; He, Q.; Ma, K.; Zhou, L. Analysis and design of a single-stage isolated AC-DC LED driver with a voltage doubler rectifier. IEEE Trans. Ind. Electron. 2017, 64, 5807-5817. [CrossRef]

17. Cheng, C.-A.; Chang, C.-H.; Cheng, H.-L.; Tseng, C.-H.; Chung, T.-Y. A single-stage high-power-factor light-emitting diode (LED) driver with coupled inductors for streetlight applications. Appl. Sci. 2017, 7, 167. [CrossRef]

18. Cheng, C.A.; Cheng, H.L.; Chang, C.H.; Yang, F.L.; Chung, T.Y. A single-stage LED driver for street-lighting applications with interleaving PFC feature. In Proceedings of the IEEE International Symposium on Next-Generation Electronics, Kaohsiung, Taiwan, 25-26 February 2013; pp. 150-152.

19. “Technical Application Guide-POWERTRONIC," OSRAM. January 2013, pp. 1-42. Available online: http://www.osram.com/ media/resource/hires/334206/technical-guide---powertronic-for-hid-lamps-gb.pdf (accessed on 30 December 2020).

20. Bellido-Outeiriño, F.J.; Quiles-Latorre, F.J.; Moreno-Moreno, C.D.; Flores-Arias, J.M.; Moreno-García, I.; Ortiz-López, M. Streetlight control system based on wireless communication over DALI protocol. Sensors 2016, 16, 597. [CrossRef] [PubMed]

21. Elejoste, P.; Angulo, I.; Perallos, A.; Chertudi, A.; Zuazola, I.J.G.; Moreno, A.; Azpilicueta, L.; Astrain, J.J.; Falcone, F.; Villadangos, J. An easy to deploy street light control system based on wireless communication and LED technology. Sensors 2013, 13, 6492-6523. [CrossRef] [PubMed]

22. Cheng, C.A.; Cheng, H.L.; Chang, C.H.; Chang, E.C.; Hung, W.S.; Lan, L.F. A novel single-stage high-power-factor LED power supply with soft-switching feature for streetlight applications. In Proceedings of the IEEE International Symposium on Computer, Consumer and Control (IS3C2020), Taichung, Taiwan, 13-16 November 2020; pp. 1-3.

23. Cheng, C.A.; Chang, C.H.; Cheng, H.L.; Chang, E.C.; Chung, T.Y.; Chang, M.T. A single-stage LED streetlight driver with soft-switching and interleaved PFC features. Electronics 2019, 8, 911. [CrossRef] 